УДК 621.396

АЛЬОШИН Г. В., д.т.н., професор,

ПАНЧЕНКО С. В., Д.Т.н, професор,

ПРИХОДЬКО С. І., д.т.н., професор

(Український державний університет залізничного транспорту)

\title{
Системний аналіз біонічної нейромережі контрастування сигналів
}

Для біологічної або біонічної моделі нейромережі контрастування на основі оптичного ефекту смуг Маха відомий крайовий контраст складних сигналів подається як прочес лінійної фільтрачї зображень. За ичи призначенням наведена конкретна фізична модель нейромережі, показники якості контрастування та особливості изього процесу.

Виявлено, щчо контрастування зображень та сигналів нейромережею є багатофункціональний процес для різних систем зі своїми призначеннями. Цим пояснюється загальне розповсюдження крайового контрасту або обробки сигналів у різних галузях природи, у науціi й техніці.

Системний аналіз нейромережі і процесів у просторово-частотній або у частотній області дає змогу виявити головні особливості процесу виділення контурів зображень, показники якості і параметри.

Розгляд структури нейромережі $і$ зв'язків «оп» або «оf» нейронів допускає можливість адаптації системи до середнього рівня яскравості зображення та економічність процесу.

Ключові слова: багатофункціональна нейромережа, системний аналіз, контрастування зображень.

\begin{tabular}{l}
\hline $\begin{array}{l}\text { Постановка проблеми системного } \\
\text { нейромереж контрастування сигналів }\end{array}$ \\
\hline
\end{tabular}

Фахівців приваблюють такі якості біологічних нейромереж зору: 1) чутливість зору, виявлення лише одного фотона у пітьмі проти п'яти і більше десятків у природній нейромережі; 2) великий динамічний діапазон можливої прийнятої яскравості; 3) швидкість обробки складного сигналу i прийняття рішень; 4) мініатюрність; 5) загальна адаптивність у системі сенсорів; 6) економічність нейромережі та інші особливості. Не всі якості біологічної нейромережі можна реалізувати в біонічній нейромережі.

Тому потрібно провести системний аналіз i дослідити головні принципи і процеси в біонічній моделі нейромережі для найбільш доцільної проблеми контрастування та розпізнавання сигналів.

Проблема в тому, щчоб на основі вже відомої біонічної моделі нейромережі сітківки провести системний аналіз ї̈ дї $і$ виявити нові якості та особливості.

\footnotetext{
Аналіз попередніх та останніх публікацій

Незважаючи на відкриття Е. Махом у 1865 році контрастних смуг, ефект оконтурювання до цього часу залишається «terra incognito».

Проте ефект широко розповсюджений у природі і в техніці, де він використовується для навмисного підвищення контрасту контурів або як супутнє явище.
}

Ефект оконтурювання зображень описано в літературі [1-7]. Проте $\epsilon$ необхідність уточнити його основні властивості, визначити критерії якості контрастування контурів, розповсюдження завдань контрастування в науці i техніці та шляхи вдосконалення моделі нейромереж.

Вивчимо ефект оконтурювання і розглянемо, яке 3 відомих математичних описів ефекту достатньо повно відображає власне явище контрастування контурів.

Відоме властивість очі підкреслювати (виділяти) контур зображення безпосередньо випливає зі структури сітківки (рис. 1) і пояснюється наявністю бічних гальмівних (латеральних «on», «of») взаємодій між елементами рецептивного поля сітківки [1-3]. На рис. 1 показані взаємні зв'язки рецептивного Однокоординатний поля для 1-го каналу. Аналогічні зв'язку для інших каналів і координат. Наявність цього бокового (латерального) гальмування в одному шарі нейронів призводить до такого відклику в каналі 3 номером «l»:

$$
F_{l}=f_{l}-\sum_{i=1}^{n} f_{i} \varphi_{l-i}
$$

де $n$ - кількість каналів;

$l$ - номер канала $l \in(0, n)$;

$f_{l}$ - яскравість вхідного зображення у $l$-му каналі або його прирощення у $l$-му каналі; 
$\varphi_{i}$ - вагова функція взаємного прямого зв'язку між каналами;

$i$ - індекс додавання, що характеризує зсув $\varphi_{i}$.

На рис. 1 позначений вхід до нейромережі з блока керування К.

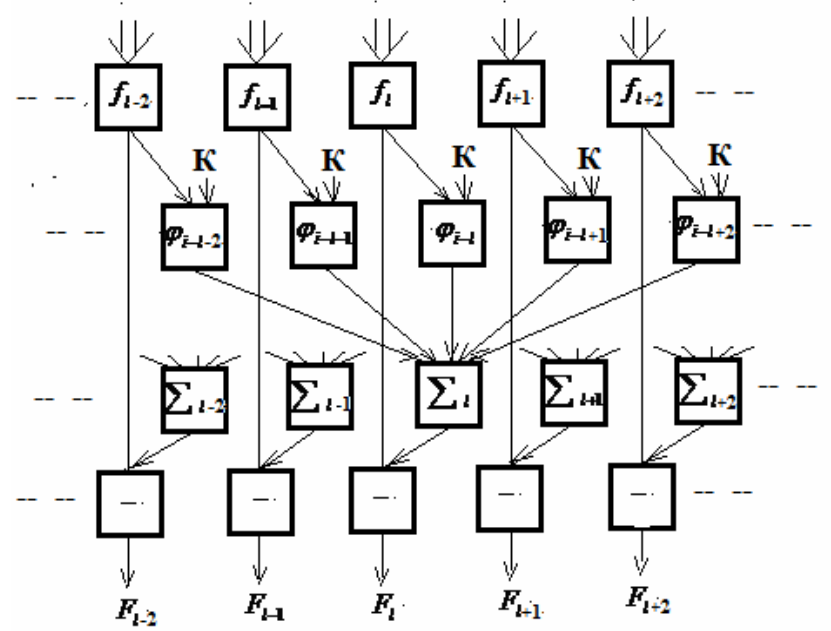

Рис. 1. Нейромережа контрастування одновимірних сигналів

Якщо максимальну апертуру рецептора $\Delta X_{1 \max }$ та максимальний зазор між сусідніми рецепторами $\Delta X_{2 \text { max }}$ зменшувати до нуля при збереженні взаємних зв'язків (1) і при збільшенні кількості рецепторів до нескінченності при заданому розмірі $D_{X}$ поля рецепторів $\quad D_{X}=\sum_{i=0}^{n}\left(\Delta X_{1 i}+\Delta X_{2 i}\right)=\sum_{i=0}^{n} \Delta X_{i}, \quad$ то отримаємо безперервний аналог одновимірного поля рецепторів з обробкою виду

$$
F(X)=f(X)-\int_{0}^{D_{X}} f\left(X_{1}\right) \varphi\left(X-X_{1}\right) d X_{1}
$$

де $X=i \Delta X=i \frac{D_{X}}{n}$, а інтеграл береться на заданому розкриві рецептивного поля або в нескінченних межах для безперервного необмеженого аналога виразу (2).

Відомий [1-6] математичний опис контрастування контурів зображень з погляду сутності ефекту в деякому сенсі неадекватний (див., наприклад, [1-4]).

У дискретній формі, близькій до (2), опис контрастування зустрічається у Ratfill та Hartline H. K. (1957). Уперше ефект контрастування контурів зображень аналітично описав Е. Max (E. Mach, 1865 р.) [1]:

$$
F(X)=\operatorname{alg}\left\{\frac{f(X)}{b} \pm \frac{-}{f(X)}\left[f^{\prime \prime}(X)\right]^{2}\right\},
$$

де $a, b, c$ - сталі.

Нелінійність виду $\lg$ описує ефект типу насичення, наприклад, вицвітання родопсину в рецепторах, стискання динамічного діапазону, замежові енергетичні можливості нейронів. Квадратична нелінійність лише загострює ефект контрасту. Для контрастування контурів у (3) характерний знак «-».

Ефект контрастування контурів добре вивчений [5-7] для одновимірної вагової функції $\varphi(X)$ з виразу (2):

$\varphi(X)=K_{1} \delta(X)+K_{2} \delta^{\prime}(X)+K_{3} \delta^{\prime \prime}(X)+\mathrm{K}$,

і найбільш виражений при $\mathrm{K}_{2} \cong 0, \mathrm{~K}_{3}<0$ i $\left|\mathrm{K}_{3}\right| \leq \mathrm{K}_{1}$.

У цьому випадку

$F(X)=K_{1} f(X)-\left|K_{3}\right| f^{\prime \prime}(X)$,

що достатньо близько до (3) i до подання ефекту контрастування контурів, яке склалося в телебаченні [5].

Опис ефекту автор Fry (1947) подавав у двовимірному вигляді

$F(x, y)=\lg \frac{a f(x, y)}{1+b V(x, y)}$,

де $V(x, y)=\iint f(x, y) \exp \left(-\frac{x^{2}}{\delta_{x}^{2}}-\frac{y^{2}}{\delta_{y}^{2}}\right) d x d y$.

Оскільки значення $V$ повинно бути меншим за 1 , то

$F(x, y) \cong \lg \left\{a f(x, y)\left[1-b V(x, y)+\frac{b^{2}}{2} V^{2}(x, y)-\mathrm{K}\right]\right\}$.

Вочевидь при гауссовій апроксимації $\varphi(x, y)$ у формулі (6) вираз у фігурних дужках (7) узгоджується iз (2). До аналогічнх висновків приводить опис ефекту у формі «шунтування» [1]. У більш простій формі (2) опис ефекту контрастування вперше згадувався у Huggins ra Licklider, Bekesy (1960) [1].

Таким чином, нелінійність функцій $F(x)$ у виразах (3), (6) описує лише супутні ефекти, а саме: автоматичне регулювання зіницею середньої інтенсивності або середньої яскравості $f_{c p}$ поля $f(x)$ 
при обробці зображень, а також ефект типу «насичення» тощо:

$$
f_{c p}=\frac{1}{D_{x}} \int_{0}^{D_{x}} f(x) d x
$$

Таким чином, ефект контрастування контурів достатньо точно описує лінійний процес у формі (1) або ( 2).

Мета статті - системний аналіз біонічної нейромережі контрастування зображень або сигналів і виявлення іiї нових якостей, призначень і функцій.

\begin{tabular}{l}
\hline Основний матеріал \\
\hline Око характеризується високою чутливістю, \\
розрішуючою здібностю, мобільністю, здатністю \\
визначати цвіт та їх відтінки у широкому діапазоні \\
довжин хвиль, значною кількістю градацій яскравості, \\
великою швидкістю розпізнавання образів. Останнє \\
звичайно відносять до особливостей мозку. Однак у \\
цьому, як вважають, бере активну участь і сама \\
сітківка. Доцільно порівнювати обробку складних \\
сигналів у нейромережах і в оптимальних радіо- \\
технічних системах (РТС).
\end{tabular}

Сітківка обробляє зображення за типом контрастування при великій яскравості сигналу або за типом узгодженої фільтрації при сутінковому баченні за слабкої яскравості. Вдень обробка зображень зовсім інша: визначення або підкреслювання контурів зображень. Імовірно, що надвечір змінюється знак виходу нейрона 3 «of» на «on» для узгодженої фільтрації. Крім того, управління функцією $\varphi_{i}$ з боку частини мозку К допомагає обробити зображення вдень, а також стиснути динамічний діапазон зображення для захисту сітківки. Таким чином, нейромережа утилізує надлишкову яскравість зображення, щзоб не було перевантажень рецепторів за рахунок вицвітання в них родопсину.

Навіщо сітківці виділяти контури зображення? Сказати, для того, щоб підвищити різкість та детальність зображення, буде мало. Організму життєво необхідно розпізнавати зображення друзів та ворогів. Найбільш корисну інформацію в зображенні мають його контури, а також їх конфігурація. Око дає змогу 3 високою точністю оцінювати також взаємне положення різних контурів. Око $є$ точним вимірювальним пристроєм. А точність вимірів визначається крутістю фронтів контурів, як відомо 3 теорії вимірювань [7].

\section{Головні особливості i функції систем} контрастування контурів зображень.

1. Узагальнений погляд на структуру нейромережі за рис.1 і іï алгоритм за формулами (1) або (2) дає змогу припускати, що іiі функції не обмежуються тільки контрастуванням контурів зображення сітківкою. Хоча така ii функція дуже важлива для біологічних і біотехнічних систем.

Біотехнічні нейромережі використовуються: 1) у кіно; 2) у телебаченні; 3) у фотографії; 4) для оконтурювання розмитих зображень; 5) для підвищення інших якостей зображення та сигналів; 6) для розпізнавання зображень; 7) для роботів; 8) для наведення крилатих ракет та ін.

Причому у техніці наведення крилатих ракет використовується формування у кожній площині двох рознесених у просторі двовимірних автокореляційних функцій контурів фазо-просторово-частотних характеристик зображень місцевості.

У цих випадках згідно із залежностями (3) та (5) вагова функція, що формується в нейромережі, на певному етапі може мати вигляд функції або iï моделі:

$$
\phi(x)=k \ddot{\delta}(x)
$$

де $\ddot{\delta}(x)$ - друга похідна від дельта-функції Дірака.

Її моделювання дає змогу вибирати і змінювати призначення, функції нейромережі i якості контрастування контурів: 1) товщину ліній контурів; 2) контраст ліній контурів; 3) ступінь оконтурювання, тобто повне виділення або часткове; 4) ступінь регулювання яскравості всього зображення або як побічний продукт.

Якість 4 може бути також додатковим засобом загальної функції регулювання яскравості, і не тільки зіницею ока. Функція 4 зберігає енергію зображення шляхом перетворення його надлишкової яскравості у підвищення контрасту контурів.

Вагова функція може бути не тільки моделлю другої похідної дельта-функції. Можлива й одномодальна модель.

Узагальнюючи, можна індуктивно $i$ достатньо ймовірно припускати, щуо для біологічних систем у природі все побудоване і працює майже оптимально.

2. 3 огляду на ці позиції, ясно, що у випадку, коли вагова функція $\varphi(x)$ рівна імпульсній характеристиці системи, значення $F(x)$ зображення нейромережі за виразом (2) $\epsilon$ різницею вхідного зображення та спотвореного мережею вихідного зображення, яким $є$ інтеграл Дюамеля, тобто на виході будь-якої нейромережі може бути вихідний сигнал як результат спотворення оконтурюванням при передачі зображення.

3. Фізична сутність очищення зображення від випадкових завад, які змінюються у часі експозиції, 
більшому від часу їх кореляції, у тому, що вихідне зображення знову подається на вхід нейромережі. При цьому процес нагадує відомий рециркулятор, де виграш у накопиченні відношення сигнал/завада залежить від кількості циклів і точності збігу зображень.

Фізичний зміст дії нейромережі, яка покращує зображення або фото, або сигнал, такий, що нейромережа може працювати за рахунок накопичення тих же зображень, але отриманих 3 розносом у часі, більшому від часу кореляції завади, де зображення збігаються, а завада випадкова. Так звана повторна «прогонка» зображень у нейромережі $\epsilon$ по суті рециркулятором.

4. Нейромережа, яка виконує функцію стирання тонких ліній, може працювати за рахунок того, що при регулюванні якості зображень товщину контурів беруть більшу, ніж у цих ліній.

5. Оцінимо якості ефекту контрастування контурів, або оконтурювання, лінійної системи (2) лише для функції включення при $x=x_{0}$. Аналогічний ефект спостерігається також на межах, зображених на рис. 2.

$f(x)=C_{1}+C_{2} 1\left(x-x_{0}\right)$,

де $C_{1}$ і $C_{2}$ - сталі;

$1\left(x-x_{0}\right)$ - одинична функція включення при $x=x_{0}$.
Назвемо символ « $k$ » параметром контрастування, а $\Delta X_{\varphi}$ - ефективною шириною вагової функції зв' язку $\varphi(x)$ з необмеженою областю визначення, яка може бути моделлю другої похідної дельта-функції Дірака. Якщо параметр $k$ дорівнює нулю, то нейросистема тільки виділяє контури зображень.

Причому

$k=\int_{-\infty}^{\infty} \varphi(x) d x$

$$
\Delta X_{\varphi}=\frac{1}{\varphi(0)} \int_{-\infty}^{\infty}|\varphi(x)| d x
$$

Ширина просторового спектра $\Delta w_{\varphi}$ вагової функції лазерного сигналу i максимальна частота відеозображення $w_{\max }$ за однією координатою рівна

$$
\Delta w_{\varphi}=\frac{1}{\Delta X_{\varphi}}
$$

Тоді на межі «тінь-світло» при $x=x_{0}$ вихідний сигнал буде:

$F(x)=C_{1}(1-k)+C_{2}\left[1\left(x-x_{0}\right)-\int_{-\infty}^{x-x_{0}} \varphi\left(x_{1}\right) d x_{1}\right]=C_{1}(1-k)+C_{2}\left[1\left(x-x_{0}\right)-\Phi\left(x-x_{0}\right)\right]$,

де $\Phi(x)=\int_{-\infty}^{x_{0}} \varphi\left(x_{1}\right) d x_{1}$.

Припустимо, що $\varphi(x)$ - парна функція, яка монотонно спадає до країв. Парність $\varphi(x)$ доцільно визначати вимогою поперечної симетричності контурних ліній як при межах «світло-тінь», так і «тінь-світло», що нескладно побачити з (12) та рис. 2.

Монотонність $\Phi(x)=\int_{-\infty}^{x_{0}} \varphi\left(x_{1}\right) d x_{1} \quad$ обумовлена вимогою відсутності «багатоконтурності» або ореола зображення. Узагалі функція $\varphi(x)$ може бути різної форми.

Розглянемо спочатку ефект оконтурювання для монотонної функції $\Phi(\mathrm{x})$.

Значення вихідного ефекту на межі «тінь-світло» 3 боку «тінь» $\mathrm{F}\left(\mathrm{x}_{0_{-}}\right)$i 3 боку «світло» $\mathrm{F}\left(\mathrm{x}_{0+}\right)$ визначаються $з$ формули (12)

$$
\sup F(x)=F\left(x_{0+}\right)=C_{1}(1-k)+C_{2}(1-k),
$$

$\inf F(x)=F\left(x_{0-}\right)=C_{1}(1-k)-C_{2} \frac{k}{2}$.

Для областей $x_{2}>x_{0}+\frac{\Delta x_{\varphi}}{2}$ i $x_{1}<x_{0}-\frac{\Delta x_{\varphi}}{2}$ значення вихідного зображення будуть мати вигляд

$$
\begin{aligned}
& F\left(x_{2}\right)=\left(C_{1}+C_{2}\right)(1-k), \\
& F\left(x_{1}\right)=C_{1}(1-k) .
\end{aligned}
$$

Якщо визначити абсолютні значення викидів «темної» $\Delta F\left(x_{0-}\right)$ та «світлої» $\Delta F\left(x_{0+}\right)$ частин контуру $\Delta F\left(x_{0}\right)$, то, користуючись формулами (13), (14), отримаємо 


$$
\begin{aligned}
& \Delta F\left(x_{0-}\right)=F\left(x_{1}\right)-\inf F\left(x_{0}\right)=C_{2} \frac{k}{2}, \\
& \Delta F\left(x_{0+}\right)=\sup F\left(x_{0}\right)-F\left(x_{2}\right)=C_{2} \frac{k}{2},
\end{aligned}
$$

тобто $\Delta F\left(x_{0-}\right)=\Delta F\left(x_{0+}\right)$.

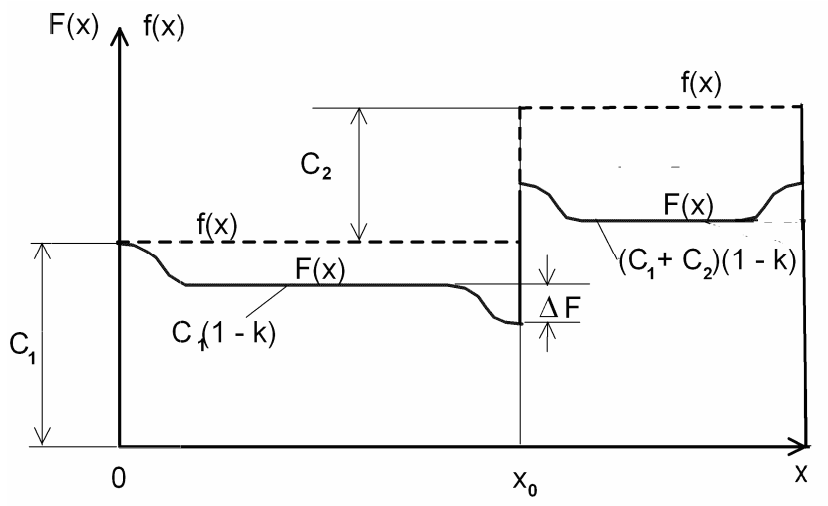

Рис. 2. Контраст контурів на межах і при $x=x_{0}$

Таким чином, 3 формули (15) випливає, що підкреслювання контурів, тобто зростання величини викидів, пропорційне величині вхідного перепаду яскравості $\mathrm{C}_{2}$ та інтегральному параметру контрастування k. Причому величини викидів не можуть бути більшими від половини вхідного перепаду яскравості, що відповідає повному виділенню контуру $(k=0)$, і рівні нулю при відсутності гальмівного зв'язку у системі або для неодномодальних вагових функцій вхідних, або без перепадів яскравості $C_{2}=0$. Умову відсутності спотворень типу «негатив» або умови позитивності вихідного зображення можна записати так:

$\inf F(x)-\Delta F\left(x_{0_{-}}\right) \geq 0$.

3 формул (13) та (15) випливає:

$k \leq \frac{1}{1+\frac{C_{2}}{2 C_{1}}} \quad$ або $\quad k \leq 1$.

Якщо оцінювати ефект контрастування контурів відомим критерієм - контрастністю $\alpha_{k}$, то для випадку (9) можна установити відповідно контрастність вхідного зображення $\alpha_{6 x}$, межі «світлотінь» $\alpha_{z p}$ і вихідного зображення за межею $\alpha_{\text {выx }}$

$$
\alpha_{B x}=\frac{\sup f(x)-\inf f(x)}{\sup f(x)+\inf f(x)}=\frac{1}{1+\frac{C_{1}}{C_{2}}},
$$

$$
\alpha_{\text {cp }}=\frac{1}{(1-k)\left(1+2 \frac{C_{1}}{C_{2}}\right)},
$$

$$
\alpha_{\text {bblx }}=\frac{1}{1+\frac{C_{1}}{C_{2}}}
$$

Визначимо ступінь контрастування $\xi$ як відносне підвищення контрасту межі «тінь-світло» порівняно 3 контрастом зображення за межею.

$\xi=\frac{\alpha_{\text {гр }}}{\alpha_{\text {вых }}}=\frac{1+\frac{\mathrm{C}_{1}}{\mathrm{C}_{2}}}{(1-\mathrm{k})\left(1+2 \frac{\mathrm{C}_{1}}{\mathrm{C}_{2}}\right)}$.

Звертаючись до будь-якої вхідної функції $f(x)$, легко відмітити, що система являє собою, як видно 3 (2), лінійний фільтр 3 імпульсною характеристикою $g(x)=\delta(x)-\varphi(x)$

$$
\begin{aligned}
& F(x)=\int_{-\infty}^{\infty} f\left(x_{1}\right)\left[\delta\left(x-x_{1}\right)-\varphi\left(x-x_{1}\right)\right] d x_{1}= \\
& =\int_{-\infty}^{\infty} f\left(x_{1}\right) g\left(x-x_{1}\right) d x_{1}
\end{aligned}
$$

Якщо $\Delta \omega_{x}-$ ефективна ширина просторовочастотного спектра зображення, то умову підкреслювання контурів запишемо таким чином:

$$
\Delta x_{\varphi} \geq \frac{1}{\Delta \omega_{x}} .
$$

При використанні системи, що оконтурює, практично завжди доводиться враховувати спостерігача або індикатора як кінцевий пристрій (термінал) 3 обмеженою розрізнювальною здатністю. Якщо вона рівна значенню $\Delta x_{p}$, то умова розрізнення контурних ліній набуде вигляду $\Delta x_{p} \leq \Delta x_{\varphi}$.

При цьому товщина контурних ліній суттєво залежить від $\Delta x_{\varphi}$, а форма викиду мало залежить від $f(x)$. 
При $k=0$ імпульсна характеристика має ту особливість, що фільтр не заглушує сталу складову сигналу. Для такої імпульсної характеристики вихідний відклик на одиничну функцію (9) має мінімум і максимум, зміщений від точки розриву $x_{0}$. Значення екстремумів та їх стаціонарні точки визначаються конкретним виглядом $\Phi(x)$.

Як і будь-який фільтр у частотній області, одновимірна система має відповідну просторочастотну характеристику

$$
S_{g}\left(\omega_{x}\right)=\underset{x}{\Varangle} g(x) \ngtr=1-\oiint_{\varphi}\left(\omega_{x}\right)
$$

де символ $\underset{x}{\Varangle}$ означає перетворення Фурьє за змінною $x$;

$$
\mathcal{S}_{\varphi}\left(\omega_{x}\right) \text { - просторово-частотна характеристика }
$$
вагової функції чи функції зв'язку $\varphi(x)$.

Просторово-частотний спектр на виході системи можна визначити:

$$
\oiint_{F}\left(\omega_{x}\right)=\&_{f}\left(\omega_{x}\right) S_{g}^{\&}\left(\omega_{x}\right)=\&_{f}\left(\omega_{x}\right)\left[1-\oiint_{\varphi}^{\&}\left(\omega_{x}\right)\right] .
$$

Навіть якісний розгляд $S_{g}\left(\omega_{x}\right)$ для випадків, коли $S_{\varphi}\left(\omega_{x}\right)$ - одномодальна крива, показує характер $S_{g}\left(\omega_{x}\right)$ як специфічного фільтра просторових частот (рис. 3).

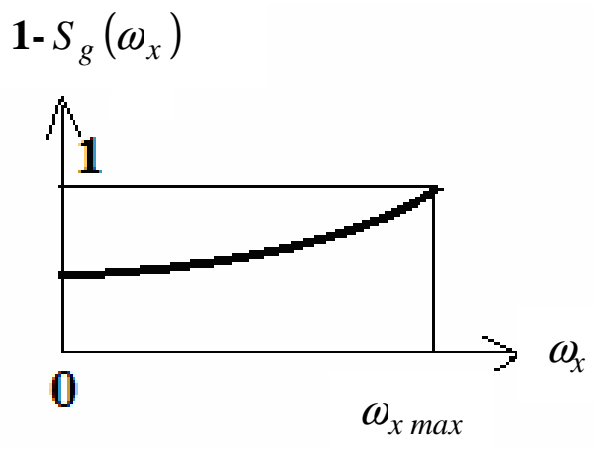

Рис. 3. Амплітудно-частотна характеристика одновимірного фільтра, що оконтурює сигнал

Принцип підкреслювання або повного виділення контурів (межі «тінь-світло») стане зрозумілим, якщо враховувати той факт, що при створенні різких перепадів яскравості (контурів) суттєву роль відіграють вищі гармоніки. Тому для фільтра 3 призначенням - підкреслювання контурів - потрібне відносне послаблення найменш інформативної, 3 погляду оцінки положення фронтів сигналу, однак, енергоємної частини спектра зображення, тобто заглушення низьких частот i сталої складової, чи навпаки, відносне підняття чи підсилення вищих частот (рис. 3).

Загальні ознаки систем, що оконтурюють, об'сднаних в один клас.

Багато систем, незважаючи на різну природу параметрів, призначення, принципів дії, структури, ефективності, мають загальну ознаку, яка дає змогу виділити в один клас системи, які використовують фізичний ефект, що оконтурює. В усіх таких системах потрібне відносне, хоча б часткове, підняття вищих частот спектра сигналу або заглушення низьких частот.

Теорію оконтурювання зображення також можна узагальнювати як теорію коливань і систем, яка має загальний характер, абстрагований від фізичної природи. У біологічній нейромережі оконтурюється також сигнал у часі в слуховому апараті.

Ефект розповсюджений і зустрічається для таких призначень і функцій у різних напрямках діяльності людини в науці, у техніці та в природі:

1) біологічні сенсорні системи - рецептори, перцептрони;

2) апертурна корекція сканувального елемента: у кіно, у телебаченні, у панорамній радіолокації;

3) техніка оконтурювання та диференціювання;

4) оптимальна фільтрація сигналів і процесів;

5) дзеркальні антени та особливо антени Касегрена для землеогляду і картографування земної поверхні;

6) фільтр Урковіца;

7) виявлення цілі в хмарах дипольних відбивачів як при наявності флуктуаційних завад, так і при їх відсутності;

8) мікроскоп Церніке: принцип фазового контрасту за рахунок чверть-хвильової проставки;

9) попередні корегувальні спотворення в системах зв'язку;

10) малокадрове телебачення;

11) багатоконтурні фільтри;

12) багатоканальний зв'язок;

13) антикореляційний метод радіолокації;

14) обробка розмитих зображень у фотографіі;

15) підсистеми 3 адаптацією до рівня сигналу в системі автоматичного регулювання підсилення (АРП);

16) розпізнавання образів;

17) методи аподизації при теоретичному синтезі антен та сигналів;

18) синтез оптимальних сигналів і систем;

19) у системах прицілювання та наведення пристроїв або ракет;

20) пояснення багатьох ілюзій зору.

Свідомо в техніці ефект оконтурювання використовується у багатьох позначених пунктах. У п. 8 i в деяких інших ефект знайдений i 
використовується на основі якогось досліду або він просто існує.

При всіх різницях призначень і реалізацій систем ефект можна розглядати як своєрідну лінійну фільтрацію зображень або сигналів у просторовочастотній області 3 ознакою амплітудно-частотної характеристики фільтра, яка зростає до меж.

\section{Висновки \\ 1. Виявлено, що фізичний ефект Е. Маха (1865) має широке застосування в природі і в техніці за різними призначеннями. \\ 2. Виявлені головні i другорядні особливості біонічної нейромережі, призначеної для підкреслювання або виділення контурів зображень і сигналів для розпізнавання зображень та для різних застосувань.}

3. Виявлено, що головною функцією біонічної нейромережі для обробки зображень є оконтурювання, яке $є$ лінійним процесом.

4. Виявлена можливість адаптивності біологічної нейромережі також до розміру середньої яскравості зображення за критерієм економії ресурсу (вицвітання родопсину).

5. Виявлений зв'язок біонічної нейромережі 3 іншими системами фільтрації зображень.

6. Із структури алгоритму біологічної мережі оконтурювання зображень випливає, що вона керується системою пам'яті та уявлення і їі неможливо представити у вигляді нейрошарів, як подається у відомих комп'ютерних нейромережах.

7. У біонічних нейромережах $\epsilon$ можливість керувати їх параметрами. Біонічна нейромережа багатофункціональна відносно призначень і адаптивна відносно показників та параметрів нейромережі.

8. Системний аналіз біонічної одновимірної нейромережі розкриває всі особливості, які притаманні також двовимірним системам.

9. Біологічна нейромережа більш варіабельна, ніж біонічна, тому що гальмівні якості зв'язків аксонів нейрона можуть легко змінюватись зі значення «of» до значення «оn» за новим призначенням.

10. Якщо вагова функція $\mathrm{g}(\mathrm{x})$ у формулі (20) імпульсною характеристикою якоїсь системи, то ця формула є інтегралом Дюамеля і відображає сигнал на ii виході. Звідси випливає, що будь-яку кількість систем можна зі спрощенням замінити однією біонічною мережею (рис. 1) 3 набором відповідних імпульсних характеристик, які подаються на розподілений вхід К на вході.

Таким чином, нейромережа (рис. 1) $\epsilon$ універсальним, економічним i адаптивним засобом обробки інформації.
Список використаних джерел

1. Ratliff F. Mach bands. Quantitative studies on neural networks in the retina. San.Francisco - LondonAmsterdam. 1965.

2. Завалишин Н. В., Мучник И. Б. Модели зрительного восприятия и алгоритмы анализа изображений. Москва: Сов. радио, 1974. 334 с.

3. Шейфис И. И. Способы улучшения качественных показателей видеотракта телевизионных сигналов. Москва: Связь, 1967. 220 с.

4. Путятин Е. П., Сердюченко В. Я. Математические модели явления краевого контраста ахроматического зрения человека (обзор). Проблемы бионики. Харьков, 1972. Вып. 9. С.219.

5. Алешин Г.В., Грабина В. А. Основные особенности системы контрастирования контуров изображений. В кн.: Проблемы бионики. Харьков, 1978. Вып. 21. С. 55.

6. Алешин Г. В., Грабина В. А. Механизм обработки информации в системах с краевым контрастом и некоторые зрительные иллюзии. В кн.: Проблемы бионики. Харьков, 1979. Вып. 22. С. 60-65.

7. Алешин Г.В., Богданов Ю.А. Эффективность сложных радиотехнических систем. Киев: Наук. думка, 2008. 288 с.

8. Алешин Г.В., Урвачев В. И. Оптическое устройство для контрастирования контуров изображений. А.С. №447957, 28.06.74 г.

Алешин Г. В., Панченко С. В., Приходько С. И. Системный анализ бионичной нейросети контрастирования сигналов.

Аннотация. Для биологической или бионической модели нейросети контрастирования на основе оптического эффекта полос Маха известный краевой контраст сложных сигналов представлен как процесс линейной фильтрации изображений. Для этого назначения приведена конкретная физическая модель нейросети, показатели качества контрастирования и особенности этого процесса.

Определено, что контрастирование изображения и сигналов нейросетью есть многофункциональный процесс для разных систем со своими назначениями.

Этим объясняется общее распространение краевого контраста или обработки сигналов в разных областях в природе, в науке и в технике.

Системный анализ нейросетей и процессов в пространственно-частотной или в частотной области позволяет определить главные особенности процесса выделения контуров изображений, показатели качества и параметры.

Изучение структуры нейросети и связей «оn» или «of» нейронов допускает возможность адаптации системы к среднему уровню яркости изображения и экономичность процесса. 
Кроме того, структура нейросети контрастирования показывает, что сетчатка имеет прямую связь ее с головным мозгом и с памятью. Она может выполнять обработку изображений подобную вычислению интеграла Дюамеля. Причем, имея в памяти большой набор весовых функций в качестве импульсных характеристик, можно получить требуемое выходное изображение. Такая нейросистема является адаптивной для разных назначений, или критериев. Она может заменять весь набор требуемых систем. Для этого достаточно оперативно их менять во времени импульсную характеристику и назначение системы.

Моделирование нейросети и процесса оконтуривания позволяет расширить возможности линейной фильтрации изображений и сигналов.

Ключевые слова: многофункциональная нейросеть, системный анализ, контрастирование изображений.

\begin{abstract}
Aloshin G. V., Panchenko S. V., Prikhodko S. I. Systemic analysis of bionic neuronet of the signal contrastion.
\end{abstract}

Abstract. There are known the biologic or bionic models of contrasting neuronet on the basis of the Mach's optic strips, or the optical end effect, where of folding signals go through the process of illumination of the image. It is discovered, that the specific physical model of neuronet is given a demonstration of contrast as the line filter process. This is a many functional process contrast of the image or the signal a for other systems with its own assignment. That will be explained in more detail to the signaling contrast of in the different applications of nature, in science and technology. The systemic analysis of the neuronet and processes in the space frequency range, or in the usual frequency do the main of the permissive details, especially the process of viewing the contour image, the indicators of aptitude and parametric.

Review of the neuronet structure and the neurons linkages "on" or "of" in admittance of adaptation system to the middle level of image and economics of the process.

In addition, the structure of the neural network contrasting shows that the retina has a direct connection with the brain and memory. It can perform image processing similar to that of the Duhamel integral. Moreover, having in mind a large set of weight functions as impulse characteristics, you can get the desired output image. Such a neural system is adaptive for different purposes, or criteria's. It can replace the entire set of required systems. To do this, it is enough to quickly change them in time impulse response and the purpose of the system.

The neuronet and process contrast modeling permit to the extension the line filtration range of the images.

Key words: many function neuronet, system analyze, contrast image.

Надійила 03.04.2019 p.
Альошин Геннадій Васильович, доктор технічних наук, професор кафедри транспортного зв'язку, Український державний університет залізничного транспорту, Харків, Украӥна. E-mail: aloshin.gennadiy@gmail.com ORCID ID https://orcid.org/0000-0003-0392-9889

Панченко Сергій Володимирович, доктор технічних наук, професор, ректор Украӥнського державного університету залізничного транспорту, Харків, Україна. E-mail: info@kart.edu.ua. https://orcid.org/0000-0002-7626-9933

Приходько Сераій Іванович, проректор з науковопедагогічної роботи, доктор технічних наук, професор, Украйнський державний університет залізничного транспорту, Харків, Україна. E-mail: prihodko@kart.edu.ua. https://orcid.org/0000-0001-6535$\underline{8351}$

Gennadiy Aloshin, Doctor of Technical Sciences, Professor of the Department of Transport Communication of the Ukrainian State University of Railway Transport, Kharkiv, Ukraine.E-mail: aloshin.gennadiy@gmail.com https://orcid.org/0000-0003-0392-9889

Sergey Panchenko, rector, Doctor of Technical Sciences, professor, Ukrainian State University of Railway Transport, Kharkiv, Ukraine. E-mail: info@kart.edu.ua. https://orcid.org/0000-0002-7626-9933

Sergey Prikhodko, Vice-rector for scientific and pedagogical work of Ukrainian State University of Railway Transport, Doctor of Technical Sciences, professor, Kharkiv, Ukraine. E-mail: prihodko@kart.edu.ua. https://orcid.org/0000-0001-6535$\underline{8351}$ 